\title{
Evaluating the effect of $\mathrm{N}$-acetylcysteine on residual renal function in chronic hemodialysis patients treated with low-flux dialysis membrane; a randomized clinical trial
}

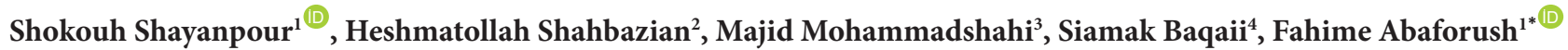 \\ ${ }^{1}$ Department of Nephrology, Chronic Renal Failure Research Center, Imam Khomeini Hospital, Student Research Committee, Ahvaz Jundishapur \\ University of Medical Sciences, Ahvaz, IR Iran \\ ${ }^{2}$ Department of Nephrology, Chronic renal Failure Research Center, Golestan Hospital, Ahvaz Jundishapur University of Medical Sciences, Ahvaz, Iran \\ ${ }^{3}$ Hyperlipidemia Research Center, Ahvaz Jundishapur University of Medical Sciences, Ahvaz, Iran \\ ${ }^{4}$ The Director of Continued Medical Education, Ahvaz Jundishapur University of Medical Sciences, Ahvaz, Iran
}

\section{A R T I C L E I N F O}

Article Type:

Original

\section{Article History:}

Received: 27 August 2017

Accepted: 24 November 2017

Published online: 13 December 2017

Keywords:

N-Acetylcysteine

Residual renal function

Hemodialysis

Peritoneal dialysis

\begin{abstract}
A B S T R A C T
Introduction: The goal of any physician who cares about dialysis patients is to increase their quality of life. Many studies have shown that residual renal function (RRF) in dialysis patients, especially those undergoing peritoneal dialysis (PD), is an important prognostic factor for mortality.

Objectives: In the present study, we aimed to investigate the effect of N-acetylcysteine (NAC) as an antioxidant on increasing RRF in chronic hemodialysis (HD) patients.

Patients and Methods: Ninety-eight chronic HD patients who have urinary output greater than $100 \mathrm{cc}$ in 24 hours participated in this study and were divided into two groups of treatment and control (49 patients each). Subsequently, the oral NAC treatment group received $600 \mathrm{mg}$ tablets twice a day before meals. The control group received placebo tablets again twice a day before meals. The duration of the study was 4 weeks.

Results: The RRF significantly improved in the treatment group during the study period, but no significant changes were observed in the control group. Residual glomerular filtration rate (GFR) rose from $1.7 \pm 0.73$ to $2.7 \pm 1.1 \mathrm{~mL} / \mathrm{min} / 1.73 \mathrm{~m}^{2}(P<0.0001)$ in the treatment group, while in the control group, there was a slight increase from $2.1 \pm 0.94$ to $2.2 \pm 1.19 \mathrm{~mL} / \mathrm{min} / 1.73$ $\mathrm{m}^{2}(P=0.26)$. Additionally, the average daily volume of urine in the treatment group increased from $594 \pm 436$ to $953 \pm 540 \mathrm{~mL} / 24 \mathrm{~h}(P<0.0001)$ in the treatment group and from $809 \pm 573$ to $771 \pm 552 \mathrm{~mL} / 24 \mathrm{~h}(P=0.11)$ in the control group. Finally, the calculation of residual renal Kt/V per week showed an increase from $0.21 \pm 0.06$ to $0.31 \pm 0.08(P<0.0001)$ in the treatment group and a decrease from $0.23 \pm 0.08$ to $0.22 \pm 0.08(P=0.22)$ in the control group.

Conclusion: Our study showed that a 4-week NAC treatment improves RRF in chronic HD patients.
\end{abstract}

Implication for health policy/practice/research/medical education:

A four-week $\mathrm{N}$-acetylcysteine treatment may improve residual renal function in chronic hemodialysis patients.

Please cite this paper as: Shayanpour S, Shahbazian H, Mohammadshahi M, Baqaii S, Abaforush F. Evaluating the effect of $\mathrm{N}$-acetylcysteine on residual renal function in chronic hemodialysis patients treated with low-flux dialysis membrane; a randomized clinical trial. J Renal Inj Prev. 2018;7(4):269-274. Doi: 10.15171/jrip.2018.60.

\section{Introduction}

One of the most important purposes of any physician who is responsible for dialysis patients is to increase their life quality. In the last two decades, numerous studies have been conducted to achieve this goal. These studies have shown that residual renal function (RRF) in dialysis patients, especially those undergoing peritoneal dialysis (PD), is an important prognostic factor for mortality $(1,2)$. For example, the CANUSA study showed that RRF, and not the dialysis dose, is an important factor for mortality 
prognosis in patients undergoing PD (1).

The benefits of RRF in dialysis patients are related to the following parameters; improved volume control, minerals and electrolytes, reduced inflammation, and increased clearance of materials bound to proteins and medium molecules $(3,4)$. The importance of RRF becomes clear when considering its effect on nutrition, cardiovascular function, mineral metabolism, and hemoglobin levels. Reduction of RRF leads to an increase in inflammation and reduces the clearance of uremic toxins, erythropoietin production, and fluid withdrawal. These effects cause anemia, malnutrition, cardiac hypertrophy, heart failure, and atherosclerosis and vascular as well as valvular calcification which may increase cardiovascular mortality and decrease the quality of life (5). In recent years, scholarly attention has been increasingly paid to the complications of inflammation, increased oxidative stress, RRF, peritoneal membrane dysfunction and clinical outcome of patients undergoing PD. It has been shown that an increased mortality rate in patients with lower renal function and higher C-reactive protein (CRP) (6) and that increased oxidative stress reduces RRF in dialysis patients. Although the exact mechanism of these complications is not yet known, it seems reasonable to look for a substance that reduces inflammation and oxidative stress but increases renal function (7). However, few studies have ever been conducted to investigate the impact of RRF on the outcome of patients undergoing hemodialysis (HD) $(2,8)$. In addition, given that the HD population accounts for at least $93 \%$ of the total dialysis population in most countries of the world, lack adequate studies in this area is a major shortcoming (9), and the preservation of RRF in dialysis patients has remained an insoluble problem (10). $\mathrm{N}$-acetylcysteine (NAC) contains a combination of sulfhydryl and its potent antioxidant effects. It is a glutathione precursor that decreases oxidative stress by increasing serum levels of antioxidants (11).

Modalities that have already been proven to better preserve RRF include 1) Using newer dialysis membranes that are high-flux biocompatible (12). 2) Using NAC as an antioxidant in HD and PD patients $(7,13)$.

\section{Objectives}

In the present study, we aimed to investigate the effect of NAC as an antioxidant on increasing RRF in chronic HD patients. Of course, we used low-flux membranes because in our HD units, the use of high-flux membranes is less feasible due to its limited availability, and most patients are under HD with low-flux membranes.

\section{Patients and Methods}

Study design

This study is a randomized double-blind controlled trial that evaluated the effect of NAC on increasing RRF and urinary output of chronic patients undergoing HD with a low-flux membrane. The subjects were chronic HD patients in Ahvaz Imam Khomeini hospital and Golestan hospital.
Inclusion criteria: 1; at least one year from the onset of dialysis. 2; having a urinary output greater than $100 \mathrm{cc}$ in 24 hours.

Exclusion criteria: 1; any acute illness that has led to hospitalization one month before or during the study. 2; a history of allergy to NAC 3; hepatic cirrhosis and/ or increased aspartate transaminase (AST) or alanine aminotransferase (ALT) 4; The use of diuretics, or any antioxidants such as previous treatment with NAC, vitamin $\mathrm{C}$ or vitamin $\mathrm{E}$, two weeks before or during the study 5; congestive heart failure with ejection fraction (EF) $<35 \%$ 6; failure to use more than $20 \%$ of the total NAC or placebo.

From among patients at different shifts, 106 eligible patients (from Imam Khomeini and Golestan hospitals), after obtaining complete descriptions and informed consent were selected.

Patients were randomly assigned to two groups of treatment and control using randomization and computer-based randomized methods. Both groups were dialyzed with dialysis machines and similar filters. Randomization was conducted by a person who was unaware of the study. The subjects were divided into two groups, 53 each. During the study, 4 patients from each group refused to continue their cooperation (less than $80 \%$ of drug use compliance). Therefore, they were excluded from the analysis, and the remaining 98 people were included in this analysis (Figure 1).

At the beginning of the study, RRF was measured by collecting 24-hour mid-week inter dialysis and by calculating glomerular filtration rate (GFR) in residual renal Kt/V. Patients emptied their bladders before starting $\mathrm{HD}$ and then began to collect urine. Urinary output was reported in $\mathrm{ml}$ per 24 hours. Blood samples for urea and creatinine were measured at the end of one session of dialysis and at the beginning of the next session. The means of urea and creatinine were used to measure creatinine clearance, and they were normalized to $1.73 \mathrm{~m}^{2}$ area of the body. Residual renal Kt/V was also calculated as weekly urea clearance adjusted for urea distribution volume. Subsequently, the oral NAC treatment group received $600 \mathrm{mg}$ tablets $\left(\right.$ Osveh $^{\mathrm{TM}}$ ) twice a day before meals. The control group received placebo tablets again twice a day before meals. The placebo tablet was similar to the NAC tablet in terms of shape, color, hardness and taste. To control the correct use of drugs, the tablets were given weekly to the patients and empty packs were delivered and counted. If the patients did not take more than $20 \%$ of the total number of drugs or placebo, they would be excluded. The duration of the study was 4 weeks, and the patients were evaluated for complications each week. After the end of the study, RRF was again measured and the data were analyzed using SPSS version 22.0.

\section{Ethical issues}

This clinical trial was approved by the ethical committee of Ahvaz Jundishapur University of Medical Sciences (code No. IR.AJUMS.REC.1394.471). The proposal which 


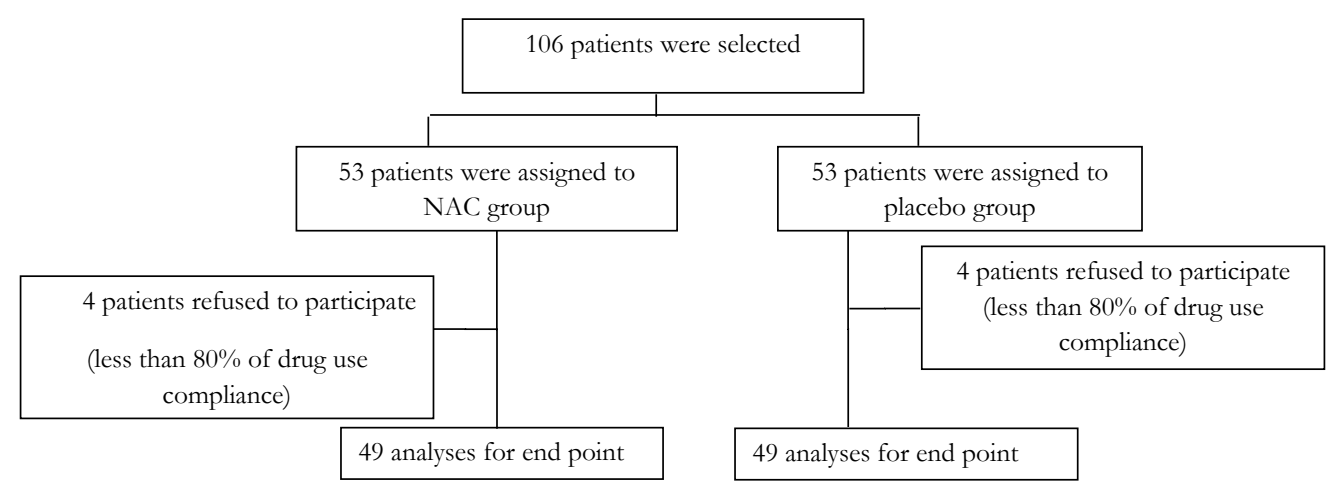

Figure 1. Flow chart of participants' assignment to the study.

is related to this trial was registered in Iranian clinical trials (identifier: IRCT2015122325675N1; http://www. irct.ir/trial/21427). The research followed the tenets of the Declaration of Helsinki too.

\section{Statistical analysis}

The results are presented as values $\pm \mathrm{SD}$. The KolmogorovSmirnov test was applied to test the normalcy of the data. The paired $t$ test was used to compare the pre-intervention and post-intervention data in a group. Student's $t$ test was used for comparison of the changes between control and intervention group. Moreover, $P$ value $<0.05$ was considered statically significant. All data were analyzed by SPSS version 22.0.

\section{Results}

Ninety-eight patients participated in this study and were divided into two groups of treatment and control (49 patients each). There were 36 male patients in each group. The mean age in the treatment and control groups was $58.6 \pm 10.6$ and $56.8 \pm 8.1$, respectively. The demographic and clinical data are presented in Table 1. The most common cause of end-stage renal disease (ESRD) was diabetes mellitus (DM). Clinical and laboratory changes between baseline values and those after 4 weeks of treatment are shown in Table 2.

The RRF significantly improved in the treatment group during the study period, but no significant changes were observed in the control group. Residual GFR rose from $1.7 \pm 0.73$ to $2.7 \pm 1.1 \mathrm{~mL} / \mathrm{min} / 1.73 \mathrm{~m}^{2}(P<0.0001)$ in the treatment group, while in the control group, there was a slight increase from $2.1 \pm 0.94$ to $2.2 \pm 1.19 \mathrm{~mL} /$ $\mathrm{min} / 1.73 \mathrm{~m}^{2}(P=0.26)$.

Also, the average daily volume of urine in the treatment group increased from $594 \pm 436$ to $953 \pm 540 \mathrm{~mL} / 24$ hours $(P<0.0001)$ in the treatment group and from $809 \pm 573$ to $771 \pm 552 \mathrm{~mL} / 24 \mathrm{~h}(P=0.11)$ in the control group.

Finally, the calculation of residual renal Kt/V per week showed an increase from $0.21 \pm 0.06$ to $0.31 \pm 0.08$ $(P<0.0001)$ in the treatment group and a decrease from $0.23 \pm 0.08$ to $0.22 \pm 0.08(P=0.22)$ in the control group.
Table 1. Characteristics of participants mean ( $\pm S D)$

\begin{tabular}{lccc}
\hline & $\begin{array}{c}\text { Treatment } \\
\text { group }\end{array}$ & $\begin{array}{c}\text { Control } \\
\text { group }\end{array}$ & P value \\
\hline Number of patients & 49 & 49 & \\
Age (y) & $58.6 \pm 10.6$ & $56.8 \pm 8.1$ & 0.3 \\
Gender, male & $36(73.5 \%)$ & $36(73.5 \%)$ & 1.0 \\
Vintage on dialysis (mon) & $31.6 \pm 16.3$ & $29 \pm 14.56$ & 0.4 \\
Cause of ESRD & & & \\
DM & $27(55.1 \%)$ & $28(57.1 \%)$ & \\
HTN & $9(18.4 \%)$ & $9(18.4 \%)$ & \\
DM+HTN & $5(10.2 \%)$ & $5(10.2 \%)$ & \\
Other & $8(16.4 \%)$ & $7(14.2 \%)$ & \\
\hline
\end{tabular}

NAC was well tolerated in this study and no adverse effects such as urticaria or hypertension were observed during treatment.

\section{Discussion}

RRF provides many advantages for ESRD patients, including a longer life span and a better quality of life (14). Reduction of RRF in these patients is a good predictor of mortality $(15,16)$. Although dialysis is the main treatment method for ESRD patients, it is not an ideal method for renal replacement therapy since it cannot completely restore renal function (17). Dialysis eliminates small soluble materials, controls and improves acidity and basicity, but cannot fully accomplish the metabolic function (18). Therefore, the preservation of RRF with better clearance of large and small molecules brings about volume control and a better metabolic and endocrine function, and this is also important even in patients who are about to start dialysis $(19,20)$. The role of RRF in reducing mortality and increasing longevity is due to its effects on the volume control and fluid balance in both HD and PD patients. In both groups, increasing the volume of fluids in chronic form increases the risk of hypertension, left ventricular hypertrophy and congestive heart failure $(21,22)$.

Nutrition and quality of life are also improved in both HD and PD patients in case of RRF preservation $(23,24)$ due to lower fluid and food intake (22). RRF is also 
Table 2. Effect of NAC on clinical characteristics and residual renal function, mean $( \pm S D)$

\begin{tabular}{|c|c|c|c|c|c|c|}
\hline \multirow[b]{2}{*}{ Urine volume, $\mathrm{mL} / 24 \mathrm{~h}$} & \multicolumn{2}{|c|}{ Treatment group } & \multirow{2}{*}{$\begin{array}{l}\boldsymbol{P} \text { value } \\
<0.0001\end{array}$} & \multicolumn{2}{|c|}{ Control group } & \multirow{2}{*}{$\begin{array}{l}\boldsymbol{P} \text { value } \\
0.11\end{array}$} \\
\hline & $594 \pm 436$ & $953 \pm 540$ & & $809 \pm 573$ & $771 \pm 552$ & \\
\hline Residual GRF, mL/min/1.73 $\mathrm{m}^{2}$ & $1.7 \pm 0.73$ & $2.7 \pm 1.1$ & $<0.0001$ & $2.1 \pm 0.94$ & $2.2 \pm 1.19$ & 0.26 \\
\hline Kt/V renal (per week) & $0.21 \pm 0.06$ & $0.31 \pm 0.08$ & $<0.0001$ & $0.23 \pm 0.08$ & $0.22 \pm 0.08$ & 0.22 \\
\hline Urine volume change & NA & $358 \pm 308$ & & NA & $-37.7 \pm 163$ & \\
\hline Residual GFR change & NA & $1.06 \pm 0.84$ & & NA & $0.15 \pm 0.93$ & \\
\hline $\mathrm{Kt} / \mathrm{V}$ renal change & NA & $0.09 \pm 0.06$ & & NA & $-0.007 \pm 0.043$ & \\
\hline
\end{tabular}

Abbreviations: NAC, N-Acetylcysteine; GFR, glomerular filtration rate; NA, not applicable.

accompanied by a better control of anemia and less need for erythropoietin (25).

Chronic inflammation is a common finding in dialysis patients and is in fact part of the pathophysiology of chronic kidney disease (26). Inflammatory mediators even increase in people with chronic renal disease who are at pre-dialysis stage and have not undergone dialysis (27). When RRF decreases, there will be an increase in inflammation due to increased oxidative stress and the activation of monocytes and cytokines in vascular endothelium $(28,29)$, which results in a faster decline of RRF (30).

As previous studies have shown, NAC treatment has supportive effects against oxidative stress and in replenishing consumed glutathione (31) and thus improves renal ischemia reperfusion (32). NAC has also protective effects on the liver and kidneys and is used as an anti-dot agent in the toxicity of acetaminophen and contrast nephropathy. It is also used as a mucolytic because of the free sulfhydryl moiety in its structure that can break glycoprotein bands in the molecule.

NAC can be used as a supplement to increase antioxidants for the two following reasons; first, its sulfhydryl group can neutralize the effects of reactive oxygen species. Second, it increases glutathione (11).

Vascular reactivity in dialysis patients is associated with elevated plasma levels of asymmetric dimethyl arginine (ADMA) and nitric oxide (NO) (33), while NAC has been shown to reduce ADMA levels in HD patients (34).

Several studies have shown NAC's effect on reducing oxidative stress and, as a result, an increase in RRF. Feldman et al in 2009, for example, found that NAC could increase RRF in PD patients (7). In this study, patients undergoing $\mathrm{PD}$ were recruited similar to our study. However, NAC was administered with a higher dose, the proportion of their patients was smaller and there was no control group compared to our study.

In 2012, Feldman et al showed an increase in RRF with NAC administration in HD patients. This study did not have any control group either, and NAC was administered with higher doses and a shorter duration (13). Therefore, by increasing the duration of the study in future studies, the effect of NAC in maintaining and increasing RRF may be even greater.

In 2013, Feldman et al compared the effect of NAC on RRF in two groups of HD patients who were dialyzed with either low-flux or high-flux membranes and concluded that RRF in patients who were dialyzed with low-flux membrane increased significantly (34). In this study, NAC was also administered with higher doses and a shorter duration, which may be due to the fact that high-flux filters reduce the amount of RRF owing to easier fluid withdrawal and higher risk of hypotension during dialysis. In this study, we investigated the effect of NAC in patients with low-flux dialysis membrane since the production of high-flux membranes in our dialysis units is difficult and most patients are dialyzed with low-flux membranes.

In our study, NAC was shown to increase RRF in HD patients treated with low-flux membranes. In the treatment group, the mean residual GFR increased by $1.06 \pm 0.84$ $\mathrm{mL} / \mathrm{min} / 1.73 \mathrm{~m}^{2}$ and the mean renal $\mathrm{Kt} / \mathrm{V}$ increased by $0.09 \pm 0.06$. Major effects of NAC on daily urine volume increased by $358 \pm 308 \mathrm{~mL} / \mathrm{d}$ after the intervention, but in the control group, the mean residual GFR increased slightly by $0.15 \pm 0.93 \mathrm{~mL} / \mathrm{min} / 1.73 \mathrm{~m}^{2}$ while the mean renal $\mathrm{Kt} / \mathrm{V}$ and the mean daily urine volume decreased by $-0.007 \pm 0.043$ and $-37.7 \pm 163$, respectively. Although the increase of RRF in the treatment group seems very slight, however, it has a very beneficial effect, clinically setting. A re-analysis of the CANUSA study showed that the relative mortality risk is reduced by about $36 \%$ for each $250 \mathrm{cc}$ increase in urinary output per day. Also, for each $0.5 \mathrm{~L} / \mathrm{wk} / 1.73 \mathrm{~m}^{2}$ (equivalent to about $0.5 \mathrm{~mL} / \mathrm{min} / 1.73 \mathrm{~m}^{2}$ ) increase in residual GFR, a $12 \%$ reduction in the relative risk of mortality is observed (1). Therefore, administration of NAC increases RRF through reducing oxidative stress in patients undergoing dialysis.

\section{Conclusion}

Our study showed that a 4-week NAC treatment improves RRF in chronic HD patients. No major complications were observed during the study period, and according to our results, NAC can be used as a complement to patients with dialysis to maintain RRF.

\section{Limitations of the study}

There were some limitations in this study that should be taken into consideration. 1; the study period was short. 2; 
in this study only HD patients were studied and further studies with more patients and longer periods are expected to yield more conclusive results.

\section{Acknowledgments}

Authors would like to thank Ms. Parisa Shehni and the dialysis staff of Imam Khomeini and Golestan hospitals who worked with us in this study.

\section{Authors' contribution}

FA, SS and HS made a substantial contribution to the conception, design, analysis and interpretation of data. SS, FA and MM were involved in drafting the manuscript and revising it critically for important intellectual content. FA analyzed the data statistically. FA, SB and SS collected the data. HS revised the manuscript critically for important intellectual content. All authors read and signed the final manuscript.

\section{Conflicts of interest}

The authors declared no potential conflicts of interest with respect to the research, authorship, and/or publication of this article.

\section{Ethical considerations}

Ethical issues (including plagiarism, data fabrication, double publication) have been completely observed by the authors.

\section{Funding/Support}

This study was extracted from the internal medicine residency thesis of Fahimeh Abaforoush and financially supported by Ahvaz Jundishapur University of Medical Sciences (thesis \# IR.AJUMS.REC.1394.471).

\section{References}

1. Bargman JM, Thorpe KE, Churchill DN, CANUSA Peritoneal Dialysis Study Group. Relative contribution of residual renal function and peritoneal clearance to adequacy of dialysis:a reanalysis of the CANUSA study. J Am Soc Nephrol. 2001;12:2158-62.

2. Brener ZZ, Thijssen S, Kotanko P, Kuhlmann MK, Bergman M, Winchester JF, et al. The impact of residual renal function on hospitalization and mortality in incident hemodialysis patients. Blood Purification. 2011;31:243-51. doi: $10.1159 / 000322252$.

3. Kabanda A, Jadoul M, Pochet JM, Pochet JM, Lauwerys R, Bernard A, et al. Determinants of the serum concentrations of low molecular weight proteins in patients on maintenance hemodialysis. Kidney Int. 1994;45:1689-96. doi: 10.1038/ ki.1994.221.

4. Delaney MP, Stevens PE, Al Hasani M, Stowe HJ, Judge C, Lamb HJ. Relationship of serum cystatin C to peritoneal and renal clearance measures in peritoneal dialysis:a cross -sectional study. Am J Kidney Dis. 2008;51:278-84. doi: 10.1053/j.ajkd.2007.08.018.

5. Wang AY, Lai KN. The importance of residual renal function in dialysis patients. Kidney Int. 2006;69:1726-32. doi: $\quad 10.1038 /$ sj.ki.5000382.
6. Chung S, Heimburger O, Stenvinkel P, Qureshi A, Lindholm B. Association between residual renal function, inflamation and patient survival in new peritoneal dialysis patients. Nephrol Dial Transplant. 2003;18:590-7. doi: 10.1093/ ndt/18.3.590.

7. Feldman L, Shani M, Efrati S, Beberashvili I, Yakov-Hai I, Abramov E, et al. N-Acetylcysteine improves residual renal function in peritoneal dialysis patients:a pilot study. Perit Dial Int. 2009;31:545-50. doi: 10.3747/pdi.2009.00263.

8. Termorshuizen F, Dekker FW, Van Manen JG, Korevaar JC, Boeschoten EW, Krediet RT. Relative contribution of residual renal function and different measures of adequacy to survival in hemodialysis patients:an analysis of the Netherlands Cooperative Study on the Adequacy of Dialysis (NECOSAD)-2. J Am Soc Nephrol. 2004;15:1061-70.

9. van de Luijtgaarden M, Noordzij M, Wanner C, Jager K. Renal replacement therapy in Europe:a summary of the 2009 ERA-EDTA annual Report. Clin Kidney J. 2012;5:109119. doi: 10.1093/ndt-plus/sfr182.

10. Moist LM, Port FK, Orzol SM, Young EW, Ostbye T,Wolfe RA, et al. Predictors of loss of residual renal function among new dialysis patients. J Am Soc Nephrol. 2000;11:556-64.

11. Shahbazian H, Shayanpour S, Ghorbani A. Evaluation of administration of oral $\mathrm{N}$-acetylcysteine to reduce oxidative stress in chronic hemodialysis patients:a double-blind, randomized, controlled clinical trial. Saudi Kidney Dis Transpl. 2016;27:88-93. doi: 10.4103/1319-2442.174084.

12. McKane W, Chandna SM, Tattersall JE, Greenwood RN, Farrington K. Identical decline of residual renal function in high-flux biocompatible hemodialysis and CAPD. Kidney Int. 2002;61:256-65. doi: 10.1046/j.1523-1755.2002.00098.x.

13. Feldman L, Shani M, Sinuani I, Beberashvili I, Weissgarten J. N-acetylcysteine improves residual renal function in hemodialysis patients:a pilot study. Hemodial Int. 2012;16:512-6. doi: 10.1111/j.1542-4758.2012.00702.x.

14. Mathew TA, Fishbane S, Obi Y, Klantar zade K. Preservation o residual kidney function in hemodialysis patients: reviving an old concept. Kidney Int. 2016;90:262-271. doi: 10.1016/j.kint.2016.02.037.

15. Brener ZZ, Kotanko P, Thijssen S, Winchester JF, Bergman $\mathrm{M}$. Clinical benefit of preserving residual renal function in dialysis patients:an update for clinicians. Am J Med Sci. 2010;339:453-456. doi: 10.1097/MAJ.0b013e3181cf7d5b.

16. Radulescu D, Ferechide D. The importance of residual renal function in chronic dialyzed patients. J Med Life. 2009;2:199-226.

17. Li PK, Cheng YL. Therapeutic option for preservation of residual renal function in patients on peritoneal dialysis. Perit Dial Int. 2007;27:158-163.

18. Nongnuch A, Assanatham M, Davenport A, Panorchan K. Strategies for preserving residual renal function in peritoneal dialysis patuents. Clin Kidney J. 2015;8:202-211. doi: $10.1093 / \mathrm{ckj} / \mathrm{sfu} 140$.

19. Li PK, Chow KM. The clinical and epidemiological aspects of vascular mortality in chronic peritoneal dialysis patients. Perit Dial Int. 2005;25:80-3.

20. Wang AY, Woo J, Wang M, Sea MM, Sabderson JE, Lui SF, et al. Important differentiation of factors that predict outcomein peritoneal dialysis patients with different degrees of residual renal function. Nephrol Dial Transplant. 2005;20:396-403. doi: 10.1093/ndt/gfh331.

21. Hassan K, Hassan S, Anwar S, Zaher A, Edgem R, Hassan F. Rredictors of left ventricular hypertrophy and their cutoffs 
in peritoneal dialysis patients. Int Heart J. 2015;56:186-191. doi: 10.1536/ihj.14-246.

22. Voroneanu L, Cusai C, Hogas S, Ardeleanu S, Onofriescu $\mathrm{M}$, Nistor I, et al. The relationship between chronic volume overload and elevated blood pressure in hemodialysis patients:use of bioimpedance provides a different perspective from echocardiography and biomarker methodologies. Int Urol Nephrol. 2010;42:789-97. doi: 10.1007/s11255-010-9767-y.

23. Suda T, Hiroshige $K$, Ohta T, Watanabe $Y$, Iwamoto $M$, Kanegae K, et al. The contribution or residual renal function to overall nutritional status in chronic hemodialysis patients. Nrphrol Dial Transplant. 2000;15:396-401.

24. Shafi T, Jaar BG, Plantinga LC, Fink NE, Sadler JH, Parekh RS, et al. Association of residual urine output with mortality, quality of life, and inflammation in incident hemodialysis patients: the Choices for Healthy Outcomes in Caring for End-Stage Renal Disease (CHOICE) study. Am J Kidney. 2010;56:348-58. doi: 10.1053/j.ajkd.2010.03.020.

25. Miyamoto T, Carrero JJ, Stenvinkel P. Inflammation as a risk factor and target for therapy in chronic kidney disease. Curr Opin Nephrol Hypertens. 2011;20:662-8. doi: 10.1097/ MNH.0b013e32834ad504.

26. Shlipak MG, Fried LF, Crump C, Bleyer AJ, Manolio TA, Tracy RP, et al. Elevation of inflammatory and procoagulant biomarkers in elderly persons with renal insufficiency. Circulation. 2003;107:87-92. doi: 10.1161/01. CIR.0000042700.48769.59.

27. Carmona AA, Rigon BG, Barroso MP, Hauser AB, Precoma $\mathrm{D}$, Bucharles $\mathrm{S}$, et al. Induction of systemic inflammation and tickening of subepicardiac arteries in an animal model of uremia. J Bras Nefrol. 2011;33:408-12. doi: 10.1590/ s0101-2800201100040004.
28. Witko-Sarsat V, Friedlander M, Nguyen KT, CapeillereBlandin C, Nguyen AT, Canteloup S, et al. Advanced oxidation protein products as novel mediators of inflammation and monocyte activation in chronic renal failure. J Immunol. 1998;161:2524-32.

29. Pecoit-Filho R, Heimburger O, Barany P, Suliman M, Lindholm B, Stenvinkel P, et al. Association between circulating inflammatory markers and residual renal function in CRF patients. Am J Kidney Dis. 2003;41:121218. doi: 10.1016/s0272-6386(03)00353-6.

30. Tepel M, Van der Giet M, Statz M, Jankowski J, Zidek W. The antioxidant acetylcysteine reduces cardiovascular events in patients with end-stage renal failure: a randomized, controlled trial. Circulation. 2003;107:987-998.

31. Heyman SN, Goldfarb M, Shina A, Karmeli F, Rosen S. N-acetylcysteine ameliorates renal microcirculation: studies in rats. Kidney Int. 2003;63:630-43.

32. Mittermayer F, Schaller J, Pleiner J, Vychytil A, Sunder-Plassmann G, Horl WH, et al. Asymmetrical dimethylarginine plasma concentrations are related to basal nitric oxide release but not endothelium-dependent vasodilation of resistance arteries in peritoneal dialysis patients. J Am Soc Nephrol. 2005;16:1832-8.

33. Thaha M, Pranawa W, Yogiantoro M, Tomino Y. Intravenous $\mathrm{N}$-acetylcysteine during hemodialysis reduces asymmetric dimethylarginine level in end-stage renal disease patients. Clin Nephrol. 2008;69:21-35.

34. Feldman L, Abu Ahmad R, Erafti S, Ashker A, Beberashvili I, Shani M. Efect of N-Acetylcysteine on residual renal function in chronic hemodialysis patients treated with high-flux synthetic dialysis membranes:a pilot study. ISRN Nephrol. 2013;2013:636208. doi: 10.5402/2013/636208.

Copyright @ 2018 The Author(s); Published by Nickan Research Institute. This is an open-access article distributed under the terms of the Creative Commons Attribution License (http://creativecommons.org/licenses/by/4.0), which permits unrestricted use, distribution, and reproduction in any medium, provided the original work is properly cited. 